\title{
Dismantling Privilege and White Supremacy in Social Work Education
}

\section{Taniko King-Jordan Karina Gil}

\begin{abstract}
The primary aim of social work is eliminating social inequalities by advocating for racial, social, and economic justice for individuals, families, groups, organizations, and communities. This commitment and promise starts in the classroom by providing opportunities for students and faculty to interact with each other and promote the core tenets of the profession. As the social work practices are shaped by the values promoted by the mainstream society, many argue that the profession is biased and does not meet the needs of Black, Indigenous People of Color (BIPOC). This issue is explored in the present study by interviewing six Black female social work faculty, aiming to elucidate their experiences in academia and the social work educational environment when interacting with their White counterparts, their students, and the administration. The findings yielded by this investigation have implications for academia, as well as social work education programs and their leadership.
\end{abstract}

Keywords: Social work, White supremacy, female faculty of color, African American, BIPOC

The primary aim of social work is eliminating social inequalities by advocating for equality for all individuals irrespective of their color, race, socio-demographic background, or any other characteristics. This commitment is reflected in the educational curricula and is further reinforced in the interactions among students and faculty in the classroom. In the United States, the Council on Social Work Education (CSWE) serves as the national association charged with advancing the quality of social work education and is recognized by the Council for Higher Education as the sole accrediting agency for the entire country (CSWE, 2021). However, as social workers make the transition from practitioners to faculty, the ideals of the profession often become skewed or disconnected as issues of race and ethnicity are exacerbated in the academic environment, where individuals are measured by the attributes dictated by the academic institution, such as academic pedigree (where they graduated), publications and impact factors, and the number of grant dollars they can secure. In this new framework, the richness of experience that social workers bring from their previous career, and their commitment to educating and inspiring students through pedagogy, or enhancing diversity and differences, no longer seem to matter. This skewed value system is particularly damaging for faculty of color, as they must grapple with different expectations and subjective judgments of their contributions. An ample body of evidence indicates that faculty of color experience devaluation of their research agendas, while being required to engage in additional activities in the areas of service to the college, department, and university (Holosko et al., 2017; Jayakumar et al., 2009). As a result, these faculty members have limited time to mentor students that come from the same cultural, racial, or ethnic background. This is particularly problematic, given that academic

Taniko King-Jordan, DSW, LMSW, former BSW Program Director and Assistant Professor, Phyllis Lan Lin Department of Social Work, University of Indianapolis, Indianapolis, IN. Karina Gil, PhD, MSW, Associate Professor, Worden School of Social Service, Our Lady of the Lake University, San Antonio, TX. 
institutions are still predominantly White and BIPOC (students) would benefit from more diverse role models.

These issues have motivated the present study, the aim of which is to gain insight into the experiences of six Black female social work faculty members. Using a narrativeidentity approach, underpinned by critical race theory (CRT) and intersectionality, their shared experiences in academia and their social work educational environment when interacting with their White counterparts, students, and administration are analyzed.

\section{History of Academia}

Academic institutions are generally perceived as safe spaces where those with inquisitive minds come to exchange their ideas and learn about philosophy, arts, and science from experts in the field. As such, academia has been celebrated as a means of advancing social mobility (Sanders, 2019). However, as all institutions are inevitably shaped by the society in which they operate, American academia was originally designed to expand the minds and the ideas of White men only, while excluding everyone else (Wilder, 2014). Thus, as Patton (2016) argued, to fully understand the present context of racism and White supremacy in higher education, it is important to acknowledge its violent, imperialistic, and oppressive past. In the same vain, Kendi (2016) used the term "uplift suasion," (p. 505) to describe the challenging position of Black people in the U.S., as they are expected to take the sole responsibility for ameliorating the negative stereotypes about race and thus minimize racism reinforced by those with power.

American academic institutions have a long history of racism and discrimination that dates back to their founding (Harris, 2015; Thelin, 2004). In the colonial area, U.S. colleges and universities financially benefitted from the slave trade, and, in order to secure further investments created curricula and conducted research that supported the enslavement of Africans (Harris, 2015). To justify such intentional perpetuation of White supremacy and power, scholars created theories and methodological approaches in favor of the racial inferiority of individuals of African descent and argued that keeping the institution of slavery was central to the nation's economic success. To make this stance morally right, they purported that enslavement would bring members of the African diaspora closer to Christian Salvation (Harris, 2015; Wilder, 2014). Coursework in history, religion, and other subjects was also aligned with these moral, economic, and political arguments (Harris, 2015). Harris (2015) found that many college campuses used or owned enslaved blacks:

who erected, and maintain the buildings and grounds, and served faculty, students, and administrators. At many schools, students, faculty, and administrators brought their slaves with them ... most students who came to these schools from all over the United States, were supporters of slavery, and some were wealthy slave owners themselves. (para. 10)

At the time, exclusion was not limited to race only, as prior to the 19th century, White women were not accepted into higher education in the U.S. (Chamberlain \& Russell Sage Foundation, 1988). Towards the end of the Civil War, faith-based religious institutions 
began to create co-educational spaces to expand higher education opportunities for women (Chamberlain \& Russell Sage Foundation, 1988). However, even after the Civil War, White Colleges continued to limit or prevent the enrollment of students of color. In the South, legal segregation prohibited the attendance of African Americans while in the North, a limited quota system was established.

At the end of the Civil War, the revisions to the Morrill Act of 1862 granted 30,000 acres of land that could be disseminated on federal land towards building an infrastructure for the education of Black Indigenous People of Color (BIPOC; Bracey, 2017; Dyson \& Smith Brice, 2016). In the early 1900s, BIPOC students were allowed to gain postsecondary degrees at these institutions (U.S. Department of Education, 1991). Even though after hard-fought court cases, such as Sweatt v. Painter in 1950 and Brown v. Board of Education in 1954, access was expanded, in the South, Black students continued to be segregated from their White counterparts. Racial segregation in educational institutions still persists and is enacted through different means such as lack of economic mobility, lack of appropriate school funding, and housing discrimination.

Consequently, social mobility as the main objective of higher education remains an elusive dream for many Black Americans (Shotwell, 2016; Walcott, 2014). Indeed, as argued by many authors, higher education continues to perpetuate White supremacy (Corley \& Young, 2018; McMahon \& Allen-Meares, 1992). In fact, Nidiffer (1999) suggests that the experiences of marginalized populations in higher education generally fall within one of five categories or a combination of these: "traditional/omission, increased inclusion, center of analysis, issue-specific, or broader social analysis" (p. 323). As a result, attempts at greater inclusion are often presented as an afterthought, rather than being guided by a broader social analysis (Mustaffa, 2017; Nicolazzo \& Marine, 2016). Consequently, the perspectives of White, male, middle/upper class individuals continue to shape the educational landscape and are promoted as the universal point of view.

These same arguments apply to social work education as well as the profession. This is aptly conveyed by McMahon and Allen-Meares (1991), who conducted a comprehensive review of pertinent literature focusing on the social work with Asian Americans, African Americans, Hispanic Americans, and Native Americans. Their analysis of 117 articles revealed that most of the research involving people of color is naïve and superficial. Similar conclusions were reached by Billingsley and Giovanni (1972), Solomon (1976), Gruber (1980), and Olsen (1982), who found that racial and ethnic minorities received differential treatment within the social welfare system. The consequences of these discriminatory practices are felt in academia, as faculty of color are made to carry a heavier burden than their White counterparts (Fields, 2007).

Given that cultural competence and expertise in interpersonal relationships are key skills for a social worker, the fact that this does not seem to apply to social workers in academia is problematic. The daily interactions of social workers, their role within the community, and their actions have lasting impacts on individuals, families, groups, communities, and organizations they purport to serve as this becomes part of the social contract, the rights, and benefits we forgo for the betterment of others (Palmer, 2010). 
Consequently, the discrepancy in higher education that delineates these tenets and values for faculty of color must be urgently addressed.

\section{A Review of Social Work Discriminatory Practices in Academia}

Social work is a profession that seeks to enhance human well-being and helps meet the basic needs of all individuals (National Association of Social Workers [NASW], 2017). As a profession embedded in a society with historical and ever-present ties to racism and oppression, its practices and the institutions charged with educating and cultivating future generations of social workers reflect these societal trends and struggles. For example, throughout the history of social work, the profession has often been criticized for failing to meet the needs of people of color (Corley \& Young, 2018; Sakamoto, 2007).

According to Schiele (2007), the evolution of social work practice and education can be segregated into four waves, the first of which spanned the 1965-1974 period and focused on the emerging concepts of race and ethnicity. In the second wave, relating to 1975-1984, focus was given to gender and race, as it coincided with the feminist movement. The third wave, spanning the 1985-1996 period, corresponded to the LGBTQI movement, championing equal rights for all people irrespective of their sexual orientation. The last wave, which commenced in 1995 and continues to the present, has a much broader focus, as it addresses the intersection of race, ethnicity, sexual orientation, physical and mental abilities, and social class (Schiele, 2007). A close look at these waves reveals that the issues affecting BIPOC and other minority groups have been neglected in social work research and practice.

Yet, despite these evident blind spots, throughout the 20th century social workers have strived to promote their professional status by demonstrating that goodwill and intentions did not necessarily translate to good social work practice, augmenting their knowledge and skills, advancing their educational curricula, establishing professional organizations vested in social justice, publishing books linking practice and theoretical social work frameworks, creating professional journals, and identifying core values all social workers should uphold (Baker Gary \& Gary, 1994). However, as a part of this initiative, the roles and contributions of Black social workers, and other racial and ethnic groups of color who played a significant role in establishing the professional status of social work, were erased (Baker Gary \& Gary, 1994). According to Gregory (2021), this practice can be attributed to the profession being predominantly White and lacking any accountability to its commitment towards social justice. As a result, academic social work continues to perpetuate racists practices (Corley \& Young, 2018; McMahon \& Allen-Meares, 1992).

These issues are further exacerbated by the fact that, for a long time, African Americans interested in pursuing specialized social work training and internships were denied access, especially in southern states (Baker Gary \& Gary, 1994). As a response to this discrimination, certain institutes sponsored short training programs to help these individuals gain the requisite knowledge, skills, and values (Baker Gary \& Gary, 1994). As these measures were clearly inadequate, in 1911, the first social work training program for Blacks was established at Fisk University (Baker Gary \& Gary, 1994). 
In the decades that followed, Black social workers significantly contributed to the profession by not only creating programs to educate the community and other social workers but also through delivery of services that had previously been neglected. In their efforts, they leveraged Black churches and other organizations, participated in mutual aid, and strategically partnered with the community to combat social problems. Some notable pioneers, such as Eva D. Bowles, Eugene Knickle Jones, Forrester B. Washington, E. Franklin Frazier, and George E. Hayes, spearheaded the profession of social work and made it a desirable profession for African Americans, yet their leadership efforts are absent from the social work history (Baker Gary \& Gary, 1994; National Association of Black Social Workers [NABSW], n.d.).

In recognition of these shortcomings, the CSWE took the initiative to spearhead the development and re-imagining of the core tenets of the profession. With the aim of promoting social, economic, and environmental justice more effectively, in 2005, a Social Work Congress convened by the NASW, the Council of Social Work Education, and the National Association of Deans and Directors, addressed racism as a part of 12 imperatives to work on over the next decade. To aid with this initiative, in 2006, NASW issued a detailed update to their statement on racism, calling upon all social workers to continuously acknowledge, recognize, and confront all forms of racism within all the institutions that are relevant to social work (NASW, 2007). Despite these efforts, the profession of social work continues to be impacted by racist ideologies (McCoy, 2020). While the field of social work has benefited from anti-blackness, violence, and institutional racism, academia still suffers from "apartheid" on knowledge, given that a large number of publications on people of color and by people of color are rejected by peer-reviewed journals (Bernal \& Villalpando, 2002). This practice has led many authors to conclude that research on racerelated themes is not valued or considered good scholarship (Bernal \& Villalpando, 2002; Holosko et al., 2017; Jayakumar et al., 2009).

This evident lack of attention and inaction on issues related to social justice brings the profession's true commitment to ending all forms of oppression into question (Bowles \& Hopps, 2014; Briggs et al., 2018; Schiele \& Hopps, 2009). The lack of social work leadership in this area has not gone unnoticed, and its silence has been categorized as "discomforting" (Allen-Meares \& Burman, 1995, p. 271) and "unnatural" (Holosko, et al., 2017, p. 273). Many authors argue that these issues stem from White ideology that neglects the experiences of people of color by adopting inappropriate research methodologies (Sakamoto, 2007; Smith, 2012; Strier, 2007) but also by failing to recognize the specifics of minority groups (Mokuau et al., 2008; Pelczarski \& Kemp, 2006), and by ignoring the contributions of scholars of color (Bernal \& Villalpando, 2002; Holosko et al., 2017; Jayakumar et al., 2009).

According to the available records, in 2016, 680,000 social workers were employed throughout the United States and this number is projected to increase by 100,000 in 2026 (Torpey, 2018). However, while a large percentage of these individuals are women and racial minorities, and the clients they serve are increasingly diverse, the number of social work faculty of color is very limited. According to the CSWE 2017 Statistics on Social Work Education in the United States, in 2017, 914 (15.7\%) full-time faculty identified as African American or Black, with only 170 (3.1\%) as Other Latino or Hispanic, 84 (1.8\%) 
as Chicano $\mathrm{r}$ Mexican American, $66(1.2 \%)$ as Puerto Rican, $53(1 \%)$ as American Indian/Native American, 390 (7.1\%) as Asian or Other Asian, and $19(0.3 \%)$ self-identified as Pacific Islander, respectively, compared with 3,474 (63.6\%) who identified as White, non-Hispanic (CSWE, 2017). Aside from the evident scarcity of BIPOC in social work departments, those that have secured their positions in academia usually tend to be in the lower echelons of the labor hierarchy (Aparicio, 2013; Charity et al., 2020; Rooney, 1987).

\section{Faculty of Color}

Although gender disparity in academia has been addressed to an extent, BIPOC faculty are still in a significant minority (Alleman et al., 2017). As a result, they are subjected to the same types of discriminatory behaviors that their communities experience daily, even if these are more subtle. As many carry the burden of being viewed as Affirmative Action hires (Fields, 2007), BIPOC faculty are expected to be twice as good at their jobs as their White counterparts (White, 2015). They are also often asked to serve on more committees and mentor students at a much higher rate, but their efforts are not recognized when it comes to promotions, evaluations, or hiring (Fields, 2007). Faculty of color must also constantly deal with disrespectful actions from students, faculty, and staff. Ample body of evidence indicates that BIPOC, especially women, are consistently given less respect in the classroom where their expertise is commonly questioned, receive negative student evaluations and feedback, and earn lower salaries (Fields, 2007). These issues are further exacerbated for BIPOC teaching courses on diversity or issues facing people of color (Fields, 2007). Furthermore, emails sent by BIPOC are less likely to receive a response if the name of the faculty sounds non-White and/or female (Jaschik, 2014).

As a result of these discriminatory practices, for many BIPOC, and specifically for women of color, race as a social construct remains a predictor for poorer outcomes (Williams, 2018). Women of color in academia lack the freedom to be authentically present and visible, as they are forced to repeatedly assert their competence and ability. According to Di'Angelo (2018), in many workplaces, there is a racial discomfort which is used to purport White sense of entitlement. This often gives rise to conscious or unconscious manipulative interactions, denoted as racelighting (Luke Wood \& Harris, 2021). Racelighting continues to have lasting implications for BIPOC because it invalidates their racialized lived experiences, forcing them to reconsider traumatic and harmful events and second-guess their experiences of it (Luke Wood \& Harris, 2021). Anderson (2017) used the term "kindling" (p. 3) to describe subtle and less visible forms of violence targeting BIPOC, which are particularly prominent in employment practices, housing discrimination, education, health care, and even the criminal justice system. For many BIPOC in academia, these persistent experiences are exhausting.

Given the complex nature of issues BIPOC face in all contexts, they should be viewed in relation to the intersections of their identities and experiences. For this reason, this research focuses on Black female social work faculty and their interactions with their White counterparts. It is worth noting that, in the history of social work, the concept of intersectionality was neither acknowledged nor explored prior to 1995 (Schiele, 2007). 
This delay in embracing this concept has had a severe impact on understanding the experiences of BIPOC individuals (Crenshaw, 1989).

The intersectionality lens can also be applied to the BIPOC experiences in the United States. According to Gil and King-Jordan (2020), intersectionality encompasses multiple identities an individual may hold that must be considered in tandem to fully understand this person's lived experience. During a presentation Kimberlé Crenshaw shared her perspective with Southbank Centre (Southbank Centre, 2016) and concurred with this view, adding that intersectionality also requires consideration of the structures that strengthen the experiences of Black women and how their narratives have been shaped by White women and Black men. For these reasons, economic, political, and social intersectionality was chosen in the present study to explore the barriers encountered by women of color.

African American women consistently contend with a plethora of racial bias that place added stressors to their ability to establish wellness (Guerra, 2013). This is especially evident in their efforts to navigate higher education. Being a female faculty of color requires that they be strong with thick skin, never showing emotion or any signs of weakness, to be assertive, but without asking too many questions. These women must perform and execute tasks at $100 \%$ all the time, and be present for every meeting, and be sure to gauge the pulse of the room as they might get called on to speak for all people of color (Sanders, 2019; Walter et al., 2011).

Thus, to better understand the experiences of Black women in academia, we must recognize race as a social construct that is embedded across structures and institutions (McCoy \& Rodrick, 2015). CRT provides a framework for understanding the experiences of BIPOC and how racial inequality is perpetuated and normalized throughout the mainstream culture (McCoy \& Rodrick, 2015). It was initially developed to address racism and as a response to structural violence occurring in the educational space following the civil rights movement (McCoy \& Rodrick, 2015). In academic research, CRT is extensively used to examine how race is viewed in education and how it should be used to embrace discourse and conversations around the idea of normalizing Whiteness (Matias et al., 2014). Therefore, it can be adopted for examining the insidiousness of White supremacy throughout the educational systems in the U.S. (Patton, 2016). The ultimate aim is prompting social work educational institutions to enact significant changes in their policies, processes, and systems to eliminate any barriers based on race.

\section{Method}

This qualitative research is a part of a larger study exploring the experiences of Black female faculty at different U.S. universities. The data for meeting its objectives was obtained from six social work faculty members that, coincidentally belonged to the same racial group (five self-identified as African American and one as of African origin). When analyzing the data, the narrative-identity approach was adopted, as proposed by McAdams (2008) who defined it as: 
Stories we construct to make sense of our lives are fundamentally about our struggle to reconcile who we imagine we were, are, and might be in our heads and bodies with who we were, are, and might be in the social contexts of family, community, the workplace, ethnicity, religion, gender, social class, and culture. (p. 242)

This data collection and analysis method was chosen, as participants were asked to share their experiences by responding in writing to an online survey, thus allowing them to consider their responses carefully and complete the survey at their own pace. Moreover, they could be assured of the confidentiality, and were thus more likely to respond truthfully. Survey participants were recruited through social networking sites focusing on faculty of color and through LinkedIn. The online survey commenced with demographic questions, followed by 13 open-ended questions focusing on experiences in academia and social work.

\section{Participants}

As previously noted, six female social work faculty took part in this study, five of whom identified as African American and one identified as an immigrant belonging to the African diaspora. The mean age of participants was 43.2. Four participants held a doctoral degree, one selected JD/MD, and one had an MSW degree. Four respondents held the rank of tenure-track assistant professor and the remaining two were non-tenured track adjunct professors. Their teaching experience was diverse, ranging from $0-2$ years (two individuals), to $10-15$ (four participants), with one person having more than 10 years of teaching experience. Four participants taught at teaching institutions and two at research institutions. Finally, four participants were employed by public and two by non-profit universities. See Table 1 for a profile of each participant and their institution.

\section{Analytical Approach}

As the responses participants provided to the survey were in digital format, they were transcribed and saved as MS Word files before being analyzed using the narrative-identity thematic approach. The analysis commenced with the organization and preparation of the data in order to obtain a general sense of the information and to facilitate the coding process, giving rise to the categories or themes that were interpreted using excerpts from participants' responses.

Next, the data were imported into the visual qualitative data management software (NVivo) and the process described above was repeated. Therefore, the data was first coded manually before using the NVivo software. Close readings of transcripts and the identification of key phrases led to further revision of generated codes, allowing themes that applied to majority of participants to emerge (Berg, 2009; Ryan \& Bernard, 2003). The following main themes were yielded by this process: "diversity of experience," "racism," "support," "superficial relationships," "sharing their pain," and "strength." Thus, findings reported in this article relate to these themes and are supported by excerpts from participants' narratives (Attride-Stirling, 2001; Maxwell, 1996; Ryan \& Bernard, 2003). 
Table 1. Participants Profile

\begin{tabular}{|c|c|c|c|c|c|c|c|}
\hline Pseudonym & $\begin{array}{c}\text { Age } \\
\text { (years) }\end{array}$ & $\begin{array}{c}\text { Terminal } \\
\text { Degree }\end{array}$ & Rank & $\begin{array}{c}\text { Administrative } \\
\text { Position }\end{array}$ & $\begin{array}{c}\text { Teaching } \\
\text { Experience (years) }\end{array}$ & Institution & $\begin{array}{c}\text { Public/ Private } \\
\text { Institution }\end{array}$ \\
\hline Participant 1 & N/A & $\mathrm{JD}, \mathrm{MD}^{*}$ & $\begin{array}{l}\text { Tenure-Track } \\
\text { Assistant Professor }\end{array}$ & Program Director & $5-10$ years & Teaching & Private-nonprofit \\
\hline Participant $2 * *$ & 37 & Ph.D. & Adjunct Instructor & No & $0-5$ years & Research & Public \\
\hline Participant 3 & 31 & Ph.D. & $\begin{array}{l}\text { Tenure-Track } \\
\text { Assistant Professor }\end{array}$ & No & $0-5$ years & Teaching & Private-nonprofit \\
\hline Participant 4 & 59 & Ph.D. & $\begin{array}{l}\text { Tenure-Track } \\
\text { Assistant Professor }\end{array}$ & No & $5-10$ years & Teaching & Public \\
\hline Participant 5 & 49 & Ph.D. & $\begin{array}{l}\text { Tenure-Track } \\
\text { Assistant Professor }\end{array}$ & $\begin{array}{l}\text { MSW Program } \\
\text { Director }\end{array}$ & $10-15$ years & Research & Public \\
\hline Participant 6 & 40 & MSW & Adjunct Instructor & $\begin{array}{l}\text { Oversight of Student } \\
\text { Success }\end{array}$ & $0-5$ years & Teaching & Public \\
\hline
\end{tabular}

*Teaches in the Social Work Department

**Immigrant belonging to the African diaspora 


\section{Data Verification and Validation}

To ensure the accuracy of study findings, as recommended by Creswell (2013), all transcripts were member-checked and were coded manually before using the NVivo software. Member-checking was conducted by sharing the results with an African American social work faculty member who did not participate in the survey and who has expertise on the subject matter. Only the results that were retained at the end of this process are reported below.

\section{Results}

"Why should my experiences in academia be any different from my everyday experiences of being Black in America?" - Participant 1

The analysis of the survey responses provided by the six participants yielded six main themes: experience with diversity, racism, support, superficial relationship, sharing the pain, and strengths. Three of these main themes were also related to sub-themes. See Table 2 for a breakdown of themes and corresponding sub-themes.

Table 2. Themes and Sub-Themes

\begin{tabular}{|l|}
\hline Experience With Diversity \\
$\bigcirc$ Ineffective \\
$\bigcirc$ Inconsistent \\
Racism \\
$\circ$ Hostility and Differential Treatment \\
Support \\
Superficial Relationships \\
Sharing the Pain \\
Strengths \\
$\circ$ Community \\
$\bigcirc$ Self-Talk \\
$\bigcirc$ Reframing \\
$\bigcirc$ Skills \\
\hline
\end{tabular}

\section{Experience With Diversity}

As participants were encouraged to describe their personal experiences with racism at their institutions, diversity was frequently discussed, often in negative terms, as strategies put in place were found to be ineffective and inconsistent. Those that labelled their institutions' efforts at promoting diversity ineffective claimed that this was perceived as mere rubber-stamping rather than a concerted effort at enacting change or making faculty of color feel welcome. Similarly, mechanisms aimed at enhancing diversity were often found inconsistent, as they focused on students and academic staff, while neglecting those in the administrative functions. 


\section{Ineffective}

When describing their institutions' efforts at promoting diversity, three participants indicated that, despite having diversity and inclusion offices or committees and offering training, they seemed incapable of establishing any real or significant changes. One individual shared, "the university has a diversity and inclusion office that is administered at the highest level of the administrative structure. However, the office does not appear to set its agenda to make the needed changes at the university." This lack of connection to the real needs of the institution seemed to be a common experience, as indicated by another participant:

I noticed my university works to offer opportunities that are diverse for students, staff, and faculty to attend. However, the diversity could expand more to encompass other groups and identities. There is no training offered on diverse groups or experiences and I believe this will be helpful for more awareness and support for faculty and students. - Participant 3

\section{Inconsistent}

The institutions' efforts were also deemed inconsistent, as there was evident incongruity between the racial and ethnic realities of the campus and the racial composition of those who held positions of power. Several participants stated that, even though student population was racially and ethnically diverse, those who held leadership and administrative positions were predominantly White. On this issue, one participant noted:

The challenge comes in with diversity in leadership and I think that impacts recruitment and retention of BIPOC students and faculty. Most who are chairs or heads of departments are White men or women. - Participant 2

Only one participant described her experiences with diversity as positive, which was ascribed to her institution being a Historically Black University.

\section{Racism}

When asked to describe their experience with racism at their institutions, five participants reported racial discrimination by students, administrators, and/or colleagues. The racism experienced by these participants ranged from microaggressions to more overt types of discrimination, but was always interpreted as hostility and differential treatment.

\section{Hostility and Differential Treatment}

When recounting their racial experiences, participants reported a variety of hostile and differential treatments. One participant described her interaction with students from rural settings as very hostile, attributing these attitudes to the absence of "any real individual experiences with people who do not look like them." She also shared that "many, not all, have challenged my knowledge of course content, refused to engage in the classroom, and [have] been outwardly hostile when they are challenged by me in the classroom." 
Several participants expressed that they had been treated differently by the university staff compared to their White counterparts, stating, "the standard I was held to was different so [by] the students as well as the chair;" reporting "microaggressions and micro assaults by faculty members and staff;" and, recounting experiences "primarily revolv[ing] around racism, discrimination, microaggressions, White supremacy in the reflection of treatment from colleagues, administration, and even students." One participant indicated that her questions or feedback have earned her a label of "difficult" as she was held to different standards compared to her White counterparts. She elaborated on this view by stating, "The rules are different, the tolerance for questions and push back is less and [I am] seen in some ways as being 'angry,' the expectations of students as well as colleagues are different."

\section{Support}

The theme of support (or lack thereof) by peers, their department, and their university, featured very prominently in the responses participants provided. One participant indicated:

[I] felt dismissed and ignored by the institution when I made overt gestures to create policies and recommendations to increase diversity awareness and practices that increased the university's intent to demonstrate equity in action. Participant 6

As those who hold leadership positions have a significant impact on whether faculty feel supported or not, it is not surprising that one participant "initially felt supported as a faculty of color but that changed when leadership changed." Some participants felt supported in their academic units, but the support was inconsistent, as indicated by the following account:

I have felt supported in my academic unit by others similarly situated to me.

However, that support does not extend to the larger university community. The

university has a conservative, Anglo-Saxon, patriarchally-led, and supported

culture that does not support those who do not conform to its beliefs, values,

language, and culture. - Participant 1

Another participant recalled having her lessons constantly revised by the chair when she started teaching a new course. As she was forced to seek help and clarification, she could sense "annoyance" in the way her requests were handled. She shared, "I would ask for meetings but there was a lack of flexibility and sometimes response, and then, of course, complaints were made about me."

Another participant revealed how challenging it is to find colleagues that will collaborate on scholarship with her, explaining "I see this happen all the time with White assistant professors but don't see this as much with Black assistant professors. Black assistant professors are often left to "fend for themselves" as they navigate the academic ladder."

Two participants, however, felt supported. In one case, this was ascribed to her faculty status at a Historically Black College. However, the other participant also noted that she 
felt supported by faculty and staff of color only, which has resulted in collaboration and co-teaching.

\section{Superficial Relationships}

Participants also described their relationships with their White social work colleagues as superficial or lacking depth. The five participants who referred to their relationship as "surface level" used the terms such as "no genuine connections," "non-existing," "very surface," and "hello, how are you [that] happens in passing or while sharing the same physical space, nothing substantial." One participant stated that she had to "manage [her] own expectations about [her] experiences with them." Another participant ascribed these superficial relationships to the sense of White privilege that is rooted in racism, explaining:

Many of these colleagues do not operate from a lens of change and believe that we have recruited both staff and students who are "not a good fit." This becomes a bias statement that simply reflects the predominant culture's perspective of an 'us and them' environment. - Participant 6

\section{Sharing the Pain}

Several participants indicated having a "need" or "want" to share their lived experiences with their White colleagues, as they lack the understanding of the obstacles their Black counterparts encounter as they navigate the academic environment. One participant expressed that she would like to tell her colleagues to "check their privilege," while another wanted to remind her colleagues that "the reality that the ivory tower was not built for someone like me to climb to the top" and that it brings "differences in expectations and treatment" to someone like her. One participant expressed, "[I am tired] of my trauma being used as a voyeuristic process for colleagues and my experiences being challenged as 'maybe they did not mean it that way or you're looking into it too much'."

\section{Strengths}

Participants spoke at length about the strength and resilience needed to survive and coexist in the social work academia. They drew upon the support of their community, as well as relied on self-talk, reframing, and other skills.

\section{Community}

For all participants, communities of support were essential in coping with institutional racism, as they were a source of strength, encouragement, and connection. In most cases, such support was offered by individuals outside of their departments and institutions, who could "validate [their] humanity and experiences." One participant shared how she has created "a unique group of friends who share ideas and opportunities to connect." She added that she also relied on several social media groups for forging such supportive partnerships. 
Several participants highlighted the importance of maintaining relationships with their mentors to help them cope and navigate academic life. One participant shared that she engages in "frequent conversations with her assigned mentor" who helps her manage uncomfortable emotions. Another individual noted that connecting with those who came before her "and successfully navigated these waters" was particularly beneficial for her.

\section{Self-Talk}

Several participants engaged in motivational self-talk to help them find strength needed to navigate and survive academia. One participant shared that she often tells herself to stop being emotional and start being more logical about her environment, as this helps her "anticipate moves from those that are hostile" towards her. Another participant is more inward-oriented, as she considers "how can I make a reasoned counter move to your move if I'm blinded by the transaction."

\section{Reframing}

Participants also found changing the way they view or think about their experiences helpful. This reframing process is an important survival skill, as it allows them to operate more effectively in academia. For example, one participant shared that she re-tooled the word "privilege" to empower her to see being African American as a privilege that allowed her to embrace her "grit and determination to succeed in the academic environment." Another participant reported that she developed "awareness that the academic ladder may not even be equipped for someone" like her, adding that it is ok to "recognize [that] your strengths can be invested in [a] different setting." One participant stated that she just stopped "expecting fair treatment," while another opined that her "uncomfortability has become routine."

\section{Skills}

All participants developed the skills they felt they needed to cope with academia, most notably resilience, strength, and management of expectations. Some participants found their voice to speak out while others learned to be more strategic and to operate with a plan. In addition, participants shared that all together, they found the "strength to persevere" and to "remain resilient against adversity."

\section{Discussion}

Based on the tenets of the social work profession, it is easy to have an idealized view of the way faculty from BIPOC communities are treated by their White colleagues. At a minimum, academic social work departments should provide an environment that ensures the well-being of all. However, the six individuals that participated in the present study had been subjected to discrimination and racism not only within their wider academic institutions but also within their social work departments. These findings corroborate the results reported by other authors (Corley \& Young, 2018; McMahon \& Allen-Meares, 
1992). Therefore, even if racial practices may have morphed to be less evident or overt, social work academia as an institution continues to hold and perpetuate racial inequality. However, this still constitutes racism that must be eradicated more effectively and systematically.

Most participants in this study were of view that the way that their academic institutions have been addressing the issues of diversity and inclusion is ineffective and inconsistent. Social work departments, as a part of large institutions and reflective of the general society, do not seem to fare any better. According to the current study participants, collegial relationships with White social work faculty seem to be plagued by microaggressive and racist practices. This finding is in line with the CRT postulates, as it acknowledges that racism is alive and well in the American society, and that the history of slavery and racism in which the academic institutions were founded persists to this day, and social work is not protected from it.

A brief overview of the history of social work confirms that the White perspective has dominated the profession. Schiele (2007) described the history of the profession in terms of four waves, indicating that the concepts of race and ethnicity were absent from the social work prior to 1965, which coincided with the emergence of the Civil Rights Movement. The three subsequent waves similarly responded to the changing social landscape, and thus explored and integrated the concepts ascribed to intersectionality, and included race, ethnicity, sexual orientation, physical and mental abilities, and social class (Schiele, 2007). The framework of intersectionality was not fully conceptualized until the fourth wave which commenced in 1995 due to the constant denial of the pervasiveness of racism and oppression in social work. As such, prominent White authors who attest to the call for social justice leveraged their power and privilege to narrate and interpret a critique on the experiences of BIPOC to make information sharing more palpable for their counterparts (Gregory, 2021). These overt acts constitute an "absent presence of Whiteness" and can be viewed as a pattern of structural violence (Gregory, 2021).

This research sheds light on the lived experiences of six Black female social work faculty as they navigate academia and interact with their White counterparts. Their accounts demonstrate that, despite having the skills and training to develop meaningful relationships with individuals from diverse groups, White social work faculty are not utilizing those skills to forge more cordial relationships with their colleagues of different race or ethnicity. This finding speaks to the realities of the social work curriculum that usually includes surface education on diversity and inclusivity. Yet, extant research on this issue remains scant.

Participants in this study described several strategies they employed to survive and navigate this hostile environment. They created plans, found social support outside of their departments and institutions, shifted their thoughts through self-talk, and developed resilience skills. In their recent study, Gil and King-Jordan (2020) examined female BIPOC's access to power and leadership, reporting that women of color who successfully secured leadership roles identified creative strategies to overcome fear that could impede their capacity to advance and progress in their respective fields. 
As expressed by the six social work faculty that contributed to this research, to live up to the values and ethics of the profession, social work departments, White faculty, and students have a lot of work to do to dismantle racism and White supremacy in social work education, which starts by recognizing that these issues exist. Moreover, to truly engender change, social work departments must be intentional in addressing this situation and must adopt strategies that are measurable, include accountability, and change culture.

If such steps are not taken, the contributions of BIPOC social work faculty will continue to be measured against different standards compared to their White peers and their place in the realm of academia will continue to be questioned by students and faculty alike (Bernal \& Villalpando, 2002; Fields, 2007; Holosko et al., 2017; Jayakumar et al., 2009). Therefore, until a systematic change takes place and their departments provide a safe space for all, they will continue to build support networks elsewhere. They will also draw upon their emotional intelligence, positive self-talk, and self-control in the face of adversity with the hope of securing their rightful place at the proverbial table. Maybe in time these amazing individuals and the obstacles they had to overcome to obtain positions that seem to come easily to their White counterparts with the same experience and education will not only be recognized fully, but championed and admired for their accomplishments.

\section{Limitations}

All studies are subject to certain limitations and this research is no exception. The main shortcoming of this investigation is a small sample of female BIPOC faculty. Thus, in future research, it would be beneficial to seek the perspectives of male BIPOC members of academia, as well as expand the sample by including social work faculty (and faculty specializing in other disciplines) from a variety of academic institutions across the country. Additionally, other research methodologies, such as ethnographies, focus groups, or faceto-face interviews, should be considered to expand upon the perspectives shared here.

\section{Implications for Social Work Educational Environment}

Social work strives to advance social and economic justice and to address issues of oppression and racism. However, the foundational practices of social work in academia have some clear racist roots and BIPOC are dealing with the consequences. Whiteness continues to permeate the field of social work, without any measures of accountability or critical self-reflection, which are clearly necessary to authentically understand the core values of social work (Gregory, 2021). The profession of social work must commit to cultivating the knowledge and skills on the intricacies of oppression and the intersections of race for BIPOC to transform and fulfill its mission of social justice (Gregory, 2021). The social work profession must do a better job with dismantling White supremacy in order to live up to its mission and honor its code of ethics. As a profession that shares a commitment to culturally competent practice, there should be an intentional emphasis on the work conducted by social justice advocates of color.

Systematic exclusion of BIPOC from academia has been normalized and social work as an academic institution must own its responsibility and rise to its mandate to ensure the 
well-being of all "with particular attention to the needs and empowerment of people who are vulnerable, oppressed, and living in poverty" (NASW, 2017, para. 1). This is achieved by affording BIPOC faculty equitable opportunities for advancement in leadership, publications, and legislative action. The profession must move away from arbitrary, yet subtle, racial violence and must embrace the diversity in all its forms (Anderson, 2017). This will ultimately illustrate a form of "good trouble" that John Lewis envisioned for our society.

\section{References}

Alleman, N., Cliburn Allen, C., \& Haviland, D. (2017). Collegiality and the collegium era of faculty differentiation. ASHE Higher Education Report, 43(4), 7122. https://doi.org/10.1002/aehe.20120

Allen-Meares, P., \& Burman, S. (1995). The endangerment of African American men: An appeal for social work action. Social Work, 40(2), 268-274. https://doi.org/10.4324/9780203789001-14

Anderson, C. (2017). White rage. Bloomsbury Publishing, Plc.

Aparicio, F. (2013). Insisting on race, ethnicity, and gender: Reflections of a Latina scholar (who is also a professor of Spanish). MLA Profession. https://profession.mla.org/insisting-on-race-ethnicity-and-gender-reflections-of-alatina-scholar-who-is-also-a-professor-of-spanish/

Attride-Stirling, J. (2001). Thematic networks: An analytic tool for qualitative research. Qualitative Research, 1, 385-405. https://doi.org/10.1177/146879410100100307

Baker Gary, G., \& Gary, L. (1994). The history of social work education for black people 1900-1930. The Journal of Sociology and Social Welfare, 21(1), 67-81. https://scholarworks.wmich.edu/cgi/viewcontent.cgi? article $=2109 \&$ context $=$ jssw

Berg, B. L. (2009). Qualitative research methods for the social sciences (7th ed.). Allyn \& Bacon.

Bernal, D. D., \& Villalpando, O. (2002). An apartheid of knowledge in academia: The struggle over the "legitimate" knowledge of faculty of color. Equity \& Excellence in Education, 35, 169-180. https://doi.org/10.1080/713845282

Billingsley, A., \& Giovannoni, J. M. (1972). Children of the storm. Harcourt Brace Jovanovich.

Bowles, D. D., \& Hopps, J. G. (2014). The profession's role in meeting its historical mission to serve vulnerable populations. Advances in Social Work, 15, 1-20. https://doi.org/10.18060/16677

Bracey, E. (2017). The significance of Historically Black Colleges and Universities (HBCUs) in the 21st Century: Will such institutions of higher learning survive? American Journal of Economics \& Sociology, 76(3), 670-696. https://doi.org/10.1111/ajes.12191 
Briggs, H. E., Holosko, M. J., Banks, L., Huggins-Hoyt, K. Y., \& Parker, J. (2018). How are African Americans currently represented in various social work venues?

Research on Social Work Practice, 28, 275-

287. https://doi.org/10.1177/1049731517706553

Brown v. Board of Education, 347 U.S. 483 (1954). https://www.loc.gov/item/usrep347483/

Chamberlain, M., \& Russell Sage Foundation. (1988). Women in academe: Progress and prospects. Russell Sage Foundation.

Charity Hudley, A. H., Mallinson, C., \& Bucholtz, M. (2020). Toward racial justice in linguistics: Interdisciplinary insights into theorizing race in the discipline and diversifying the profession. Language, 96(4), e200-e235. https://doi.org/10.1353/lan.2020.0074

Corley, N. A., \& Young, S. M. (2018). Is social work still racist? Social Work, 63(4), 317-326. https://doi.org/10.1093/sw/swy042

Council on Social Work Education [CSWE]. (2017). 2017 statistics on social work education in the United States. https://www.cswe.org/Research-Statistics/ResearchBriefs-and-Publications/CSWE_2017_annual_survey_reportFINAL.aspx\#: :text=BSW\%20AT\%2DA\%2DGLANCE\&text=Programs\%20reporte d \%20a \%20total $\% 20$ enrollment, (44.2\%25\%3B $\% 20208 \% 20$ programs).

CSWE. (2021). About CSWE. CSWE. https://www.cswe.org/About-CSWE

Crenshaw, K. (1989). Demarginalizing the intersection of race and sex: A Black feminist critique of antidiscrimination doctrine, feminist theory, and antiracist politics. University of Chicago Legal Forum. https://doi.org/10.4324/9780429500480-5

Di'Angelo, R. (2018). White fragility: Why is it so hard for white people to talk about racism? Beacon Press.

Dyson, Y., \& Smith Brice, T. (2016). Embracing the village and tribe: Critical thinking for social workers from an African-Centered Approach. Journal of Social Work Education, 52(1), 108-117. https://doi.org/10.1080/10437797.2016.1112648

Fields, C. D. (2007, June 23). A morale dilemma - black professors on white campuses. Diverse. https://diverseeducation.com/article/7747/

Gil, K., \& King-Jordan, T. (2020). Woman and power: Exploring the intersections of race, ethnicity, and culture. In D. Rosser-Mims, J. R. McNellis, J. Johnson-Bailey, \& C. Egan (Eds.), Pathways into the political area: The perspectives of global women leaders (pp. 47-66). Information Age Publishing Inc.

Gregory, J. R. (2021). Social work as a product and project of whiteness, 1607-1900. Journal of Progressive Human Services, 32(1), 17-36. https://doi.org/10.1080/10428232.2020.1730143

Gruber, M. L. (1980). Inequality in the social services. Social Service Review, 54, 59-75. 
Guerra, M. (2013, November 7). Fact sheet: The state of African American women in the United States. Center for American Progress. https://www.americanprogress.org/issues/race/reports/2013/11/07/79165/fact-sheetthe-state-of-african-american-women-in-the-united-states/

Harris, L. M. (2015, March 26). The long, ugly history of racism at American universities. The New Republic. https://newrepublic.com/article/121382/forgottenracist-past-american-universities

Holosko, M. J., Briggs, H. E., \& Miller, K. M. (2017). Do black lives really matter-to social work? Introduction to the special edition. Research on Social Work Practice, 28, 272-274. https://doi.org/10.1177/1049731517706551

Jaschik, S. (2014, April 24). The bias for white men. Inside Higher Ed. https:/www.insidehighered.com/news/2014/04/24/study-finds-faculty-members-aremore-likely-respond-white-males-others

Jayakumar, U. M., Howard, T. C., Allen, W. R., \& Han, J. C. (2009). Racial privilege in the professoriate: An exploration of campus climate, retention, and satisfaction. Journal of Higher Education, 80, 538-563. https://doi.org/10.1353/jhe.0.0063

Kendi, I. (2016). Stamped from the beginning: The definitive history of racist ideas in America. National Books.

Luke Wood, J., \& Harris III, F. (2021, February 12). Racelighting: A prevalent version of gaslighting facing people of color. Diverse Issues in Higher Education. https://diverseeducation.com/article/205210/

Matias, C., Mitchell Viesca, K., Garrison-Wade, D., Tandon, M., \& Galindo, R. (2014). "What is critical whiteness doing in our nice field like critical race theory?" Applying CRT and CWS to understand the white imaginations of white teacher candidates. Equity and Excellence in Education, 47(3), 289-304. https://doi.org/10.1080/10665684.2014.933692

Maxwell, J. A. (1996). Qualitative research design: An interactive approach. Sage.

McAdams, D. P. (2008). Personal narratives and the life story. In O. P. John, R. W. Robins, \& L. A. Pervin (Eds.), Handbook of personality: Theory and research (3rd ed., pp. 242-262). Guildford Press.

McCoy, D., \& Rodrick, D. (2015). Critical race theory in higher education: 20 years of theoretical and research innovations. ASHE Higher Education Report, 41(3), 1-15. https://doi.org/10.1002/aehe.20021

McCoy, H. (2020). Black lives matter, and yes, you are racist: The parallelism of the twentieth and twenty-first centuries. Child and Adolescent Social Work Journal, 37(463-475). https://doi.org/10.1007/s10560-020-00690-4

McMahon, A., \& Allen-Meares, P. (1992). Is social work racist? A content analysis of recent literature. Social Work, 37, 533-539. https://doi.org/10.1093/sw/37.6.533 
Mokuau, N., Garlock-Tuialiì, J., \& Lee, P. (2008). Has social work met its commitment to Native Hawaiians and other Pacific Islanders? A review of the periodical literature. Social Work, 58, 115-121. https://doi.org/10.1093/sw/53.2.115

Mustaffa, J. B. (2017). Mapping violence, naming life: A history of anti-Black oppression in the higher education system. International Journal of Qualitative Studies in Education, 30(8), 711-727. https://doi.org/10.1080/09518398.2017.1350299

National Association of Black Social Workers. (n.d.). NABSW pioneers. https://www.nabsw.org/page/Pioneers

National Association of Social Workers [NASW]. (2007). Institutional racism \& the social work profession: A call to action. https://www.socialworkers.org/LinkClick.aspx?fileticket=SWK1aR53FAk\%3D\&por $\underline{\text { talid }=0}$

NASW. (2017). Code of ethics of the National Association of Social Workers. https://www.socialworkers.org/About/Ethics/Code-of-Ethics/Code-of-Ethics-English

Nicolazzo, Z., \& Marine, S. B. (2016). Teaching the history of US higher education: A critical duoethnography. Journal for the Study of Postsecondary and Tertiary Education, 1, 215-232. https://doi.org/10.28945/3530

Nidiffer, J. (1999). Poor historiography: The "poorest" in American higher education. History of Education Quarterly, 39(3), 321-336. https://doi.org/10.2307/370013

Olsen, L. (1982). Services for minority children in out-of-home care. Social Service Review, 56, 572-585. https://doi.org/10.1086/644048

Palmer, R. (2010). The perceived elimination of affirmative action and the strengthening of Historically Black Colleges and Universities. Journal of Black Studies, 40(4), 762776. https://doi.org/10.1177/0021934708320729

Patton, D. (2016). Disrupting postsecondary prose: Towards a critical race theory of higher education. Urban Education, 51(3), 315-342. https://doi.org/10.1177/0042085915602542

Pelczarski, Y., \& Kemp, S. P. (2006). Patterns of child maltreatment referrals among Asian and Pacific Islander families. Child Welfare, 85, 5-31.

Rooney, B. (1987). Resistance to change. Liverpool Merseyside Area Profile Group/ Race and Social Policy Unit - Liverpool University.

Ryan, G. W., \& Bernard, H. R. (2003). Techniques to identify themes. Field Methods, 15, 85-109. https://doi.org/10.1177/1525822X02239569

Sakamoto, I. (2007). An anti-oppressive approach to cultural competence. Canadian Social Work Review, 24(1), 105-114. https://www.jstor.org/stable/41669865

Sanders, J. (2019, March 26). Black women, let your anger out: Chronic stress is killing us we can't keep repressing our rage. In These Times. 
http://inthesetimes.com/article/21775/black-women-anger-chronic-stress-ragerepression-discrimination-racism

Schiele, J., \& Hopps, J. (Eds.). (2009). Racial minorities then and now: The continuing significance of race [Special Issue]. Social Work, 54(3), 195-199. https://doi.org/10.1093/sw/54.3.195

Schiele, J. H. (2007). Implications of the equality of oppressions paradigm for curriculum content on people of color. Journal of Social Work Education, 43(1), 83-100. https://doi.org/10.5175/jswe.2007.200400478

Shotwell, A. (2016). Against purity: Living ethically in compromised times. University of Minnesota Press. https://doi.org/10.1080/09687599.2017.1372946

Smith, L. T. (2012). Decolonizing methodologies: Research and indigenous peoples. Zed Books.

Solomon, B. B. (1976). Black empowerment: Social work oppressed communities. Columbia University Press. https://doi.org/10.1093/sw/22.3.234

Southbank Centre. (2016, March 14). Kimberlé Crenshaw-on Intersectionality-Keynote WOW 2016 [Video]. YouTube. https://www.youtube.com/watch?v=-DW4HLgYP1A

Strier, R. (2007). Anti-oppressive research in social work: A preliminary definition. British Journal of Social Work, 37, 857-871. https://doi.org/10.1093/bjsw/bcl062

Sweatt v. Painter, 339 U.S. 629. (1950). https://www.lexisnexis.com/community/casebrief/p/casebrief-sweatt-v-painter

Thelin, J. R. (2004). A History of the American higher education. The Johns Hopkins University Press.

Torpey, E. (2018). Careers in social work: Outlook, pay, and more. U.S. Bureau of Labor Statistics. https://www.bls.gov/careeroutlook/2018/article/social-

workers.htm\#: :text=Employment\%20and\%20outlook,families\%20or\%20worked\%2 0in\%20schools

U.S. Department of Education. (1991). Historically Black Colleges and Universities and higher education desegregation. https://www2.ed.gov/about/offices/list/ocr/docs/hq9511.html

Walcott, R. (2014). The problem of the human: Black ontologies and 'the coloniality of our being.' In S. Brock \& C. Junker (Eds.), Postcoloniality - decoloniality - Black critique: Joints and fissures (pp. 93-105). University of Chicago Press.

Walter, M., Taylor, S., \& Habibis, D. (2011). How white is social work in Australia? Australian Social Work, 64(1), 6-19. https://doi.org/10.1080/0312407x.2010.510892

White, G. B. (2015). Black workers really do need to be twice as good. The Atlantic. https://www.theatlantic.com/business/archive/2015/10/why-black-workers-really-doneed-to-be-twice-as-good/409276/ 
Wilder, C. S. (2014). Ebony and ivy: Race, slavery and the troubled history of America's universities. Bloomsbury.

Williams, J. (2018). Race and poverty: Growth areas for social work research agenda. Social Work Research, 42(2), 67-70. https://doi.org/10.1093/swr/svy009

Author note: Address correspondence to Taniko King-Jordan, Phyllis Lan Lin Department of Social Work. 1400 E. Hannah Ave., Indianapolis, IN. 46227. Email: kingjordant@uindy.edu or Karina Gil, Worden School of Social Service, Our Lady of the Lake University, 411 S. W. 24th St, San Antonio, TX 78207. Email: Kegil@ollusa.edu 